\title{
Sistem Pakar untuk Diagnosa Penyakit Ayam Pedaging
}

\author{
Wiwik Kusrini $^{1}$, Fathurrahmani ${ }^{2}$, Rabini Sayyidati ${ }^{3}$. \\ ${ }^{1,2,3}$ Program Studi Teknologi Informasi, Politeknik Negeri Tanah Laut \\ email:wiwik.kusrini@politala.ac.id, fathurrahmani@politala.ac.id, \\ rsayyidati@politala.ac.id
}

(Received: 8 Oktober 2020 / Accepted: 27 November 2020/ Published Online: 20 Desember)

\begin{abstract}
Abstrak
Kabupaten Tanah Laut merupakan penghasil ayam pedaging terbanyak di Kalimantan Selatan. Akan tetapi pengetahuan masyarakat tentang gejala maupun penyakit pada ayam masih kurang, sehingga ini menjadi masalah yang harus diselesaikan karena dapat menimbulkan kerugian. Oleh karena itu dilakukan penelitian dengan tujuan untuk mengatasi masalah tersebut yaitu dengan dibangun sebuah aplikasi sistem pakar yang dapat digunakan oleh masyarakat dan penyuluh untuk melakukan diagnosa penyakit ayam. Metode yang digunakan untuk membangun sistem ini adalah waterfall dengan teknik forward chaining sebagai solusi runut maju artinya inferensi dilakukan dengan mencari data masukan berupa data gejala berupa penyakit ayam. Sistem yang dibangun dilengakapi dengan fitur yang menampilkan solusi pengobatan penyakit dan pencegahannya berdasarkan gejala-gejala yang telah dimasukkan, sehingga ayam yang terserang penyakit dapat ditangani dengan tepat dan cepat sesuai dengan penyakitnya. Berdasarkan pengujian blackbox yang dilakukan dengan melibatkan calon pengguna diperoleh hasil bahwa semua fungsionalitas dapat berjalan sesuai dengan yang diharapkan. Pengujian akurasi juga dilakukan dengan membandingkan perhitungan manual dengan nilai akurasi sebesar 95\%. Hal ini dipengaruhi oleh pemberian bobot nilai gejala yang mempengaruhi turunnya nilai hasil gejala jika dibandingkan dengan keadaan ideal. Kesimpulannya implikasi dari penggunaan sistem ini dapat memberikan kemudahan bagi masyarakan dan penyuluh dalam melakukan diagnosa penyakit ayam.
\end{abstract}

Kata kunci: Sistem Pakar, Ayam Pedaging, Rule, Black Box

\begin{abstract}
Tanah Laut Regency is the largest producer of broilers in South Kalimantan. However, public knowledge about symptoms and diseases in chickens is still lacking, so this is a problem that must be resolved because it can cause losses. Therefore, this research was conducted with the aim of overcoming this problem, namely by building an expert system application that can be used by the public and extension workers to diagnose chicken disease. The method used to build this system is a waterfall with the forward chaining technique as a forward-looking solution, meaning that inference is done by looking for input data in the form of symptom data in the form of chicken disease. The system built is equipped with features that display disease treatment and prevention solutions based on the symptoms that have been entered, so that disease-stricken chickens can be handled appropriately and quickly according to their disease. Based on blackbox testing carried out by involving potential users, the results obtained that all functionality can work as expected. Accuracy testing is also done by comparing manual calculations with an accuracy value of 95\%. This is influenced by the weighting of the symptom value which affects the decrease in the value of the symptom result when compared to ideal conditions. In conclusion, the implications of using this system can make it easier for the community and instructor to diagnose chicken disease.
\end{abstract}

Keywords: Expert System, Broiler, Rule, Black Box 


\section{PENDAHULUAN}

Unggas merupakan salah satu hewan yang banyak dipelihara oleh warga masyarakat Kabupaten Tanah Laut. Populasi unggas yang paling banyak dipelihara tersebut adalah ayam dan itik. Bahkan di Kabupaten Tanah Laut sendiri merupakan penghasil ayam terbanyak di Kalimantan Selatan dengan total populasi 51.375 .593 ekor pada tahun 2017 (BPS, 2017). Meskipun demikian warga masyarakat masih minim terhadap pengetahuan pada gejala maupun penyakit yang sering terjadi pada unggas terutama jenis ayam pedaging.

Penyakit merupakan salah satu resiko yang harus selalu dihadapi oleh peternak ayam pedaging setiap tahunnya, maka dari itu diperlukan pengetahuan yang memadai yang berkaitan dengan gejala dan penyakit yang sering muncul terjadi pada ayam pedaging. Namun untuk mengetahui dan membedakan gejala maupun penyakit pada ayam pedaging tergolong agak sulit karena masing-masing penyakit yang ada memiliki kemiripan gejala. Hal ini menyebabkan peternak menjadi tergantung pada pakar unggas atau dokter hewan yang ahli dalam menangani berbagai macam penyakit unggas yang dapat memberikan kemudahan bagi peternak untuk mengetahui gejala dan penyakit yang timbul pada ayam pedaging dengan mudah agar dapat meminimalisir resiko yang mengakibatkan kerugian. Permasalahan yang terdapat dalam penelitian ini yaitu bagaimana membangun sebuah sistem pakar yang dapat digunakan untuk melakukan diagnosa terhadap gejala dan penyakit yang sering terjadi pada ayam pedaging. Sistem pakar merupakan suatu sistem yang menirukan pengetahuan manusia dan menerjemahkan ke dalam komputer guna memodelkan kemampuan untuk menyelesaikan masalah seperti layaknya seorang pakar (Septiani \& Kuryanti, 2019). Sistem pakar itu merupakan suatu sistem yang didalamnya dimasukan berbagai pengetahuan yang berasal dari seorang ahli sehingga dapat digunakan oleh user dalam melakukan berkonsultasi. Salah satu metode yang digunakan dalam membuat sistem pakar adalah metode forward chaining (Fuad \& Susilo, 2016). Russel dan Norvig memberikan penjelasan bahwa metode forward chaining merupakan metode pencarian atau teknik pelacakan runut maju ke depan dimana pelacakan dimulai dengan informasi yang ada dan penggabungan rule untuk menghasilkan suatu kesimpulan atau tujuan yang diharapkan (Ariyawan, 2018). Forward chaining merupakan metode pencarian atau teknik pelacakan ke depan yang dimulai dengan informasi atau fakta yang berupa data selanjutnya bergerak maju melalui premis-premis dan penggabungan rule untuk menghasilkan suatu kesimpulan (booton up reasoning). Menurut (Ibrohim \& Purwanty, 2017) forward chaining merupakan suatu metode yang dimulai dengan mengumpulkan sejumlah fakta-fakta yang ada kemudian dari kumpulan fakta-fakta tersebut akhirnya dapat menghasilkan sebuah kesimpulan. Selain itu Sistem pakar merupakan sistem komputer yang mensimulasi, atau bertindak dalam segala hal, dengan kemampuan pengambilan keputusan seperti manusia ahli (pakar) (Salman \& Abu-Naser, (2019).

Aplikasi sistem pakar ini dapat membatu warga masyarakat, peternak maupun Dinas Peternakan dan Kesehatan Hewan untuk melakukan diagnosa suatu penyakit yang terdapat pada ayam pedaging. Selain itu aplikasi sistem pakar juga dapat digunakan oleh masyarakat maupun peternak untuk menambah informasi dan pengetahuan tentang gejala dan penyakit yang terdapat pada ayam pedaging. Adapun tujuan lain yang dicapai dalam penelitian ini yaitu membangun sebuah sistem pakar berbasis web yang dapat diakses secara online untuk melakukan diagnosa terhadap gejala dan penyakit yang sering terjadi pada ayam pedaging.

Penelitian terkait yang telah dilakukan sebelumnya dilakukan untuk identifikasi penyakit ayam pedaging (Afandi, 2018). Penelitian tersebut dibangun berbasis desktop dengan menggunakan Microsoft Visual Basic 6.o dan Microsoft SQL Server 2000. Data yang digunakan dalam penelitian tersebut hanya terdiri dari 20 data gejala dan 8 data penyakit. Penelitian serupa juga dilakukan oleh (Rohajawati \& Supriyati, 2010), yang berjudul Sistem Pakar: Diagnosis Penyakit Unggas Dengan Metode Certainty Factor. Penelitian tersebut menggunakan 37 data gejala serta 6 data penyakit. Sistem yang dibangun bertujuan untuk 
mengurangi kerugian yang diakibatkan oleh penyebarluasan penyakit. Penelitian lain dilakukan untuk mendiagnosa penyakit alergi pada anak di kota Batam dengan menggunakan metode Forward Chaining (Jarti \& Trisno, 2017). Aplikasi yang dibangun melakukan diagnosa penyakit berdasarkan gejala yang dimasukkan oleh pengguna. Keluaran yang dihasilkan oleh aplikasi tersebut berupa data penyakit.

Berdasarkan hal tersebut di atas maka penelitian ini bertujuan membangun sistem pakar untuk mendiagnosis penyakit ayam pedaging yang dijadikan memberikan solusi bagi peternak, masyarakat maupun penyuluh hewan ternak untuk dapat digunakan untuk mengenali gejala serta penyakit yang biasanya terdapat pada ayam pedaging agar dapat meminimalisir kerugian. Dengan sistem pakar yang dibangun ini pengetahuan yang dimiliki oleh seorang pakar dapat disimpan didalam komputer yang kemudian dapat digunakan oleh orang lain untuk melakukan konsultasi mengenai suatu gejala dan kemudian dapat menyimpulkan atau mendapatkan suatu hasil berdasarkan suatu gejala yang dimilikinya.

\section{METODE}

Metode yang digunakan dalam pengembangan sistem pakar untuk diagnosa penyakit ayam pedaging ini adalah metode waterfall atau yang biasa disebut metode air terjun. Metode ini merupakan metode sederhana yang menyediakan pendekatan alur hidup sistem/perangkat lunak secara terurut (Sukamto \& Shalahuddin, 2016). Tahapan pada metode waterfall yang digunakan dapat dilihat pada gambar 1.

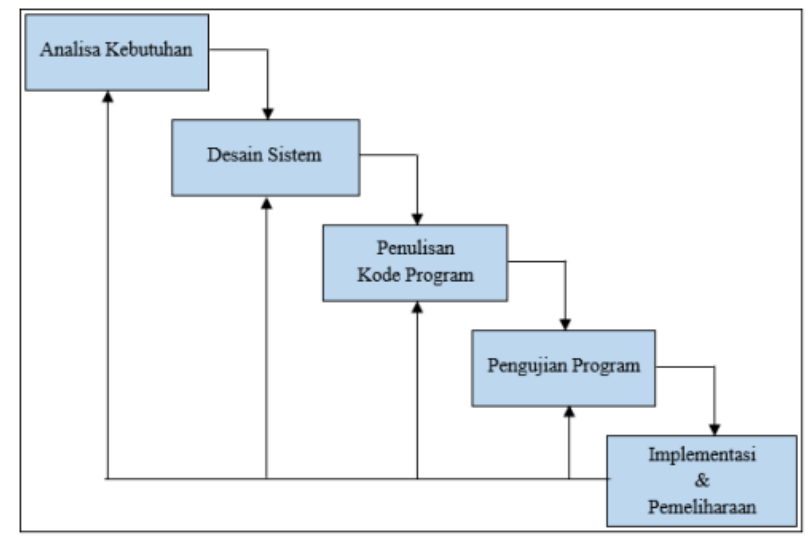

Gambar 1. Metode Waterfall

Tahap awal dalam pengembangan sistem pakar ini dimulai dengan melakukan analisa terhadap kebutuhan. Pada tahap ini juga dilakukan pengumpulan data yang diperlukan dengan mempelajari literature yang berkaitan dengan gejala dan penyakit pada ayam pedaging, serta melakukan wawancara kepada pakar, penyuluh kesehatan hewan dan juga peternak unggas. Tahap berikutnya dilakukan desain sistem atau perancangan perangkat lunak. Pada tahap ini peneliti melakukan perancangan basis data dengan membuat entity relationship diagram (ERD), perancangan alur data dengan membuat data flow diagram (DFD), perancangan terhadap proses dengan membuat flowchart, serta perancangan tampilan atau desain user interface.

Setelah tahap desain sistem selesai dilakukan maka dilanjutkan dengan pengkodean menggunakan bahasa pemrograman PHP dan database My SQL. Metode forward chaining dimasukkan dituangkan ke dalam kode program untuk agar dapat digunakan untuk penelusuran rule gejala sehingga dapat disimpulkan penyakit yang ada pada ayam. Kemudian dilanjutkan dengan pengujian terhadap fungsionalitas sistem yang telah dibuat dengan metode black box untuk menguji fungsionalitas sistem. Pengujian terhadap metode forward chaining juga dilakukan yaitu dengan membandingkan dengan perhitungan manual dengan 
perhitungan yang ada pada sistem. Tahap terakhir yaitu mengimplementasikan sistem agar dapat digunakan oleh masyarakat, peternak, penyuluh kesehatan hewan dan seorang pakar dengan melakukan pengunggahan ke hosting.

\section{HASIL DAN PEMBAHASAN}

Hasil

\section{Basis Pengetahuan}

Tabel 1 adalah basis pengetahuan di dalamnya berisi pengetahuan yang diperlukan dalam memahami maupun membuat formulasi dan memecahkan suatu masalah (Ifriza \& Djuniadi, 2015). Basis pengetahuan dimulai dengan melakukan proses akuisi pengetahuan seorang pakar dan diteruskan dengan merancang table serta pohon keputusan dan aturan produksi (Firmansyah \& Putra, 2017). Basis pengetahuan pada metode forward chaining dilakukan dengan melakukan pencocokan terhadap pernyataan atau fakta secara runut dari kiri (If-Then) ke kanan atau dengan runut maju. Penalaran diawali dari sejumlah fakta untuk mengetahui hasil kesimpulan atau kebenaran dari hipotesis.

Data dan informasi penunjang dalam penelitian yang telah berhasil dikumpulkan diantaranya adalah data gejala dan data penyakit yang sering terjadi pada ayam pedaging. Data tersebut kemudian dijadikan sebagai pendukung untuk merepresentasikan pengetahuan dari pakar dan sebagai dasar untuk membuat rule. Pada penelitian ini ditentukan 13 rule atau aturan yang disimpan didalam basis pengetahuan. Berdasarkan rule gejala untuk penentuan penyakit diatas selanjutnya dapat dilakukan penelusuran menggunakan metode forward chaining. Data gejala yang telah diinputkan tersebut kemudian akan diproses didalam sistem dengan metode forward chaining berdasarkan rule yang telah ditentukan. Basis pengetahuan yang direpresentasikan dalam penelitian ini yaitu menggunakan penelusuran dengan kaidah IF - THEN. Contohnya untuk menemukan penyakit Asites yaitu: "IF sesak nafas AND nafsu makan menurun AND perut membesar berisi air AND bulu kasar AND malas bergerak THEN Asites". Rule gejala untuk menentukan penyakit dapat dilihat pada Tabel 1.

Setelah rule direpresentasikan menggunakan tabel keputusan maka selanjutnya dibuat dengan menggunakan pohon keputusan dengan tujuan memberikan kemudahan dalam melakukan penelusuran atau pelacakan ke depan berdasarkan informasi atau fakta yang berupa data selanjutnya bergerak maju melalui premis-premis dan penggabungan rule untuk menghasilkan suatu kesimpulan (booton up reasoning). Kesimpulan yang diperoleh berupa data menyakit ayam.

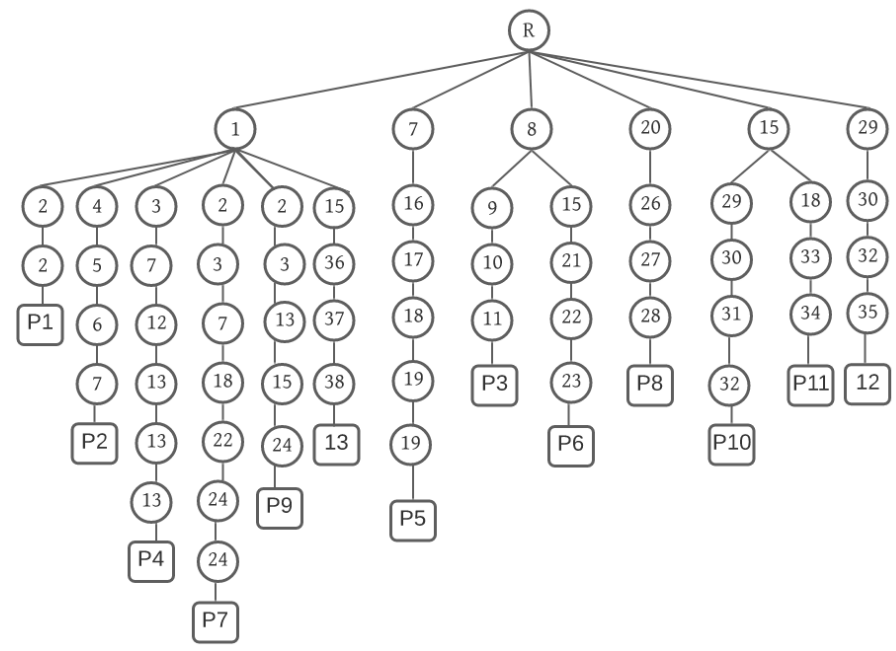

Gambar 2. Pohon Penelusuran Penyakit 
Tabel 1. Rule Gejala untuk Menentukan Penyakit

\begin{tabular}{|c|c|c|c|c|c|c|c|c|c|c|c|c|c|c|}
\hline \multirow[t]{2}{*}{ No } & \multirow[t]{2}{*}{ Gejala } & \multicolumn{13}{|c|}{ Penyakit } \\
\hline & & $\begin{array}{l}\hat{\theta} \\
\dot{a} \\
\dot{a}\end{array}$ & $\begin{array}{l}\frac{0}{0} \\
0 \\
\frac{0}{0} \\
\tilde{0} \\
0=0 \\
0 \\
1 \\
0 \\
0\end{array}$ & 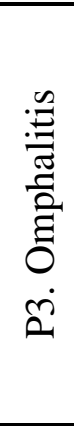 & 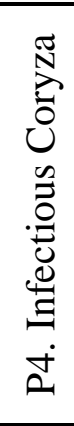 & $\begin{array}{l}\frac{\pi}{0} \\
\frac{\pi}{0} \\
\frac{0}{U} \\
\frac{3}{0} \\
\check{0} \\
\check{0}\end{array}$ & $\begin{array}{l}\text { 응 } \\
\vdots \\
\Xi \\
0 \\
0 \\
0\end{array}$ & 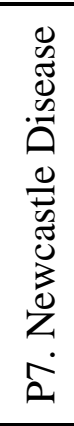 & 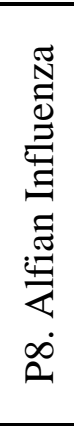 & 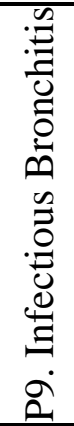 & 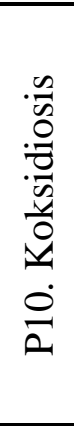 & 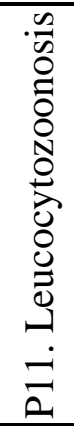 & 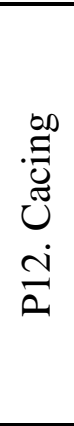 & $\begin{array}{l}\frac{\omega}{5} \\
\frac{0}{4} \\
\dot{n} \\
\frac{n}{2}\end{array}$ \\
\hline 1 & Gejala 1 & $\mathrm{x}$ & $\mathrm{x}$ & & $\mathrm{x}$ & & & $\mathrm{x}$ & & $\mathrm{x}$ & & & & $\mathrm{x}$ \\
\hline 2 & Gejala 2 & $\mathrm{x}$ & & & & & & $\mathrm{x}$ & & $\mathrm{x}$ & & & & \\
\hline 3 & Gejala 3 & $\mathrm{x}$ & & & $\mathrm{x}$ & & & $\mathrm{x}$ & & $\mathrm{x}$ & & & & \\
\hline 4 & Gejala 4 & & $\mathrm{x}$ & & & & & & & & & & & \\
\hline 5 & Gejala 5 & & $\mathrm{x}$ & & & & & & & & & & & \\
\hline 6 & Gejala 6 & & $\mathrm{x}$ & & & & & & & & & & & \\
\hline 7 & Gejala 7 & & $\mathrm{x}$ & & $\mathrm{x}$ & $\mathrm{x}$ & & $\mathrm{x}$ & & & & & & \\
\hline 8 & Gejala 8 & & & $\mathrm{x}$ & & & $\mathrm{x}$ & & & & & & & \\
\hline 9 & Gejala 9 & & & $\mathrm{x}$ & & & & & & & & & & \\
\hline 10 & Gejala 10 & & & $\mathrm{x}$ & & & & & & & & & & \\
\hline 11 & Gejala 11 & & & $\mathrm{x}$ & & & & & & & & & & \\
\hline 12 & Gejala 12 & & & & $\mathrm{x}$ & & & & & & & & & \\
\hline 13 & Gejala 13 & & & & $\mathrm{x}$ & & & & & $\mathrm{x}$ & & & & \\
\hline 14 & Gejala 14 & & & & $\mathrm{x}$ & & & & & & & & & \\
\hline 15 & Gejala 15 & & & & $\mathrm{x}$ & & $\mathrm{x}$ & & & $\mathrm{x}$ & $\mathrm{x}$ & $\mathrm{x}$ & & $\mathrm{x}$ \\
\hline 16 & Gejala 16 & & & & & $\mathrm{x}$ & & & & & & & & \\
\hline 17 & Gejala 17 & & & & & $\mathrm{x}$ & & & & & & & & \\
\hline 18 & Gejala 18 & & & & & $\mathrm{X}$ & & $\mathrm{x}$ & & & & $\mathrm{x}$ & & \\
\hline 19 & Gejala 19 & & & & & $\mathrm{x}$ & & & & & & & & \\
\hline 20 & Gejala 20 & & & & & $\mathrm{x}$ & & & $\mathrm{x}$ & & & & & \\
\hline 21 & Gejala 21 & & & & & & $\mathrm{x}$ & & & & & & & \\
\hline 22 & Gejala 22 & & & & & & $\mathrm{x}$ & $\mathrm{x}$ & & & & & & \\
\hline 23 & Gejala 23 & & & & & & $\mathrm{x}$ & & & & & & & \\
\hline 24 & Gejala 24 & & & & & & & $\mathrm{x}$ & & $\mathrm{x}$ & & & & \\
\hline 25 & Gejala 25 & & & & & & & $\mathrm{x}$ & & & & & & \\
\hline 26 & Gejala 26 & & & & & & & & $\mathrm{x}$ & & & & & \\
\hline 27 & Gejala 27 & & & & & & & & $\mathrm{x}$ & & & & & \\
\hline 28 & Gejala 28 & & & & & & & & $\mathrm{x}$ & & & & & \\
\hline 29 & Gejala 29 & & & & & & & & & & $\mathrm{x}$ & & $\mathrm{x}$ & \\
\hline 30 & Gejala 30 & & & & & & & & & & $\mathrm{x}$ & & $\mathrm{x}$ & \\
\hline 31 & Gejala 31 & & & & & & & & & & $\mathrm{x}$ & & & \\
\hline 32 & Gejala 32 & & & & & & & & & & $\mathrm{x}$ & & $\mathrm{x}$ & \\
\hline 33 & Gejala 33 & & & & & & & & & & & $\mathrm{x}$ & & \\
\hline 34 & Gejala 34 & & & & & & & & & & & $\mathrm{x}$ & & \\
\hline 35 & Gejala 35 & & & & & & & & & & & & $\mathrm{x}$ & \\
\hline 36 & Gejala 36 & & & & & & & & & & & & & $\mathrm{x}$ \\
\hline 37 & Gejala 37 & & & & & & & & & & & & & $\mathrm{x}$ \\
\hline 38 & Gejala 38 & & & & & & & & & & & & & $\mathrm{x}$ \\
\hline
\end{tabular}


Pohon penelusuran penyakit merupakan desain dari proses untuk mengambil suatu keputusan dari suatu penyakit (Ongko, 2013). Gambar 2 merupakan pohon penelusuran penyakit berdasarkan gejala. Sebagai contoh penelusuran gejala dan penyakit yang ada pada gambar 2 pohon keputusan penelusuran penyakit adalah "IF 8 AND 15 AND 21 AND 22 AND 23 THEN P6". Artinya jika gejala yang terdapat pada ayam adalah "gejala 15, gejala 21, gejala 22 dan gejala 23, maka dapat disimpulkan bahwa penyakit yang diderita ayam tersebut adalah penyakit dengan kode P6 yang merupakan penyakit gumboro.

\section{Entity Relationship Diagram (ERD)}

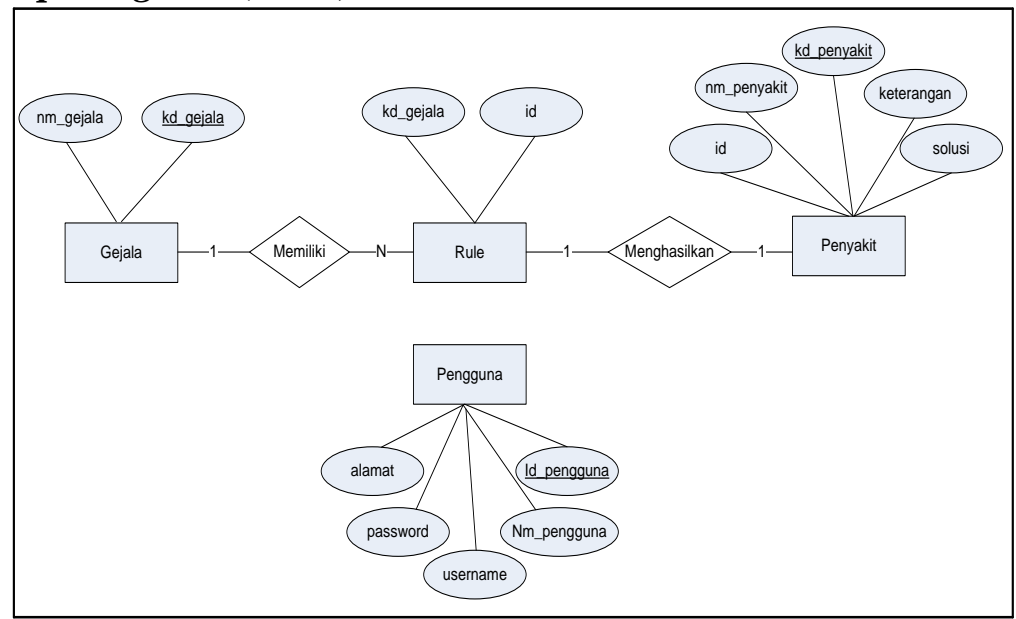

Gambar 2. Entity Relationship Diagram (ERD)

Rancangan entity relationship diagram terdiri dari empat entitas. Pertama entitas adalah Gejala yang mempunyai dua atribut yaitu nm_gejala dan kd_gejala. Entitas kedua adalah Rule yang mempunyai dua atribut yaitu kd_gejala dan id. Entitas ketiga adalah Penyakit mempunyai lima atribut yaitu id, nm_penyakit, kd_penyakit, keterangan dan solusi. Entitas terkhir adalah Pengguna yang mempunyai atribut alamat, password, username, nm_pengguna dan id_pengguna.

\section{Data Flow Diagram (DFD)}

Data Flow Diagram (DFD) level 1 mendeskripsikan 6 proses yang ada pada system yaitu proses login, kelola data pengguna, kelola data penyakit, kelola data diagnosa, kelola data rule, kelola data gejala, dan logout. Data Flow Diagram (DFD) yang digunakan dalam penelitian ini dapat dilihat pada gambar 3 .

\section{Implementasi}

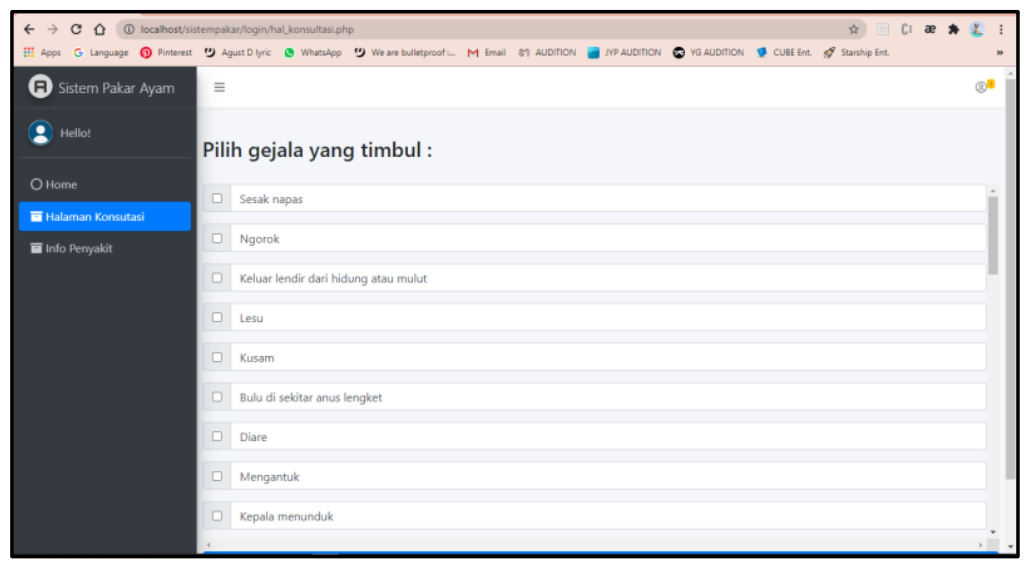

Gambar 4. Tampilan Menu Halaman Konsultasi 


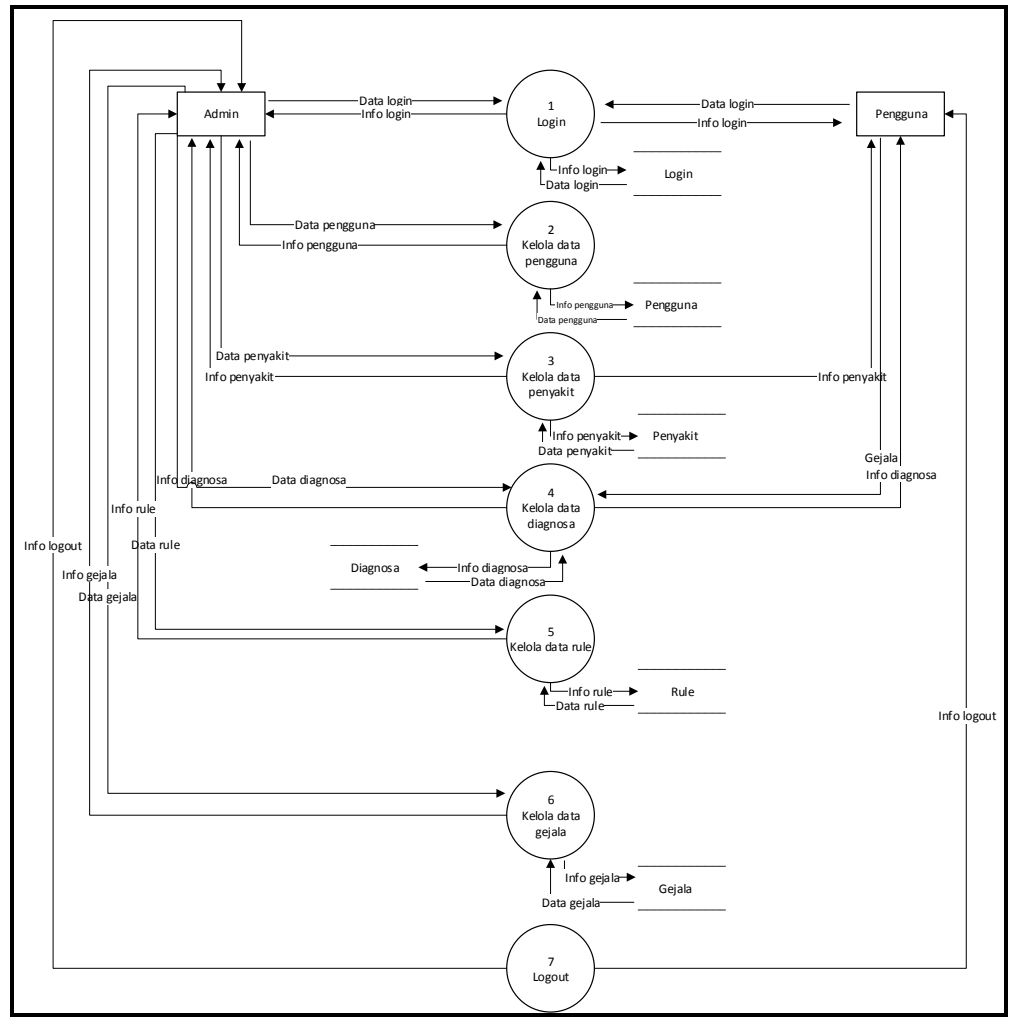

Gambar 3. Data Flow Diagram (DFD)

Gambar 4 merupakan tampilan menu halaman konsultasi yang dapat diakses oleh masyarakat maupun oleh penyuluh. Selanjutnya gambar 5 merupakan tampilan hasil diagnose berdasarkan konsultasi masukan gejala yang dilakukan oleh user. Halaman ini dapat diakses oleh masyarakat maupun oleh penyuluh. Sementara itu, untuk mengetahui hasil atau daftar mengenai penyakit apa saja yang terjadi pada ayam pedaging adalah dapat dilihat pada menu info penyakit yang diilustrasikan pada gambar 6 .

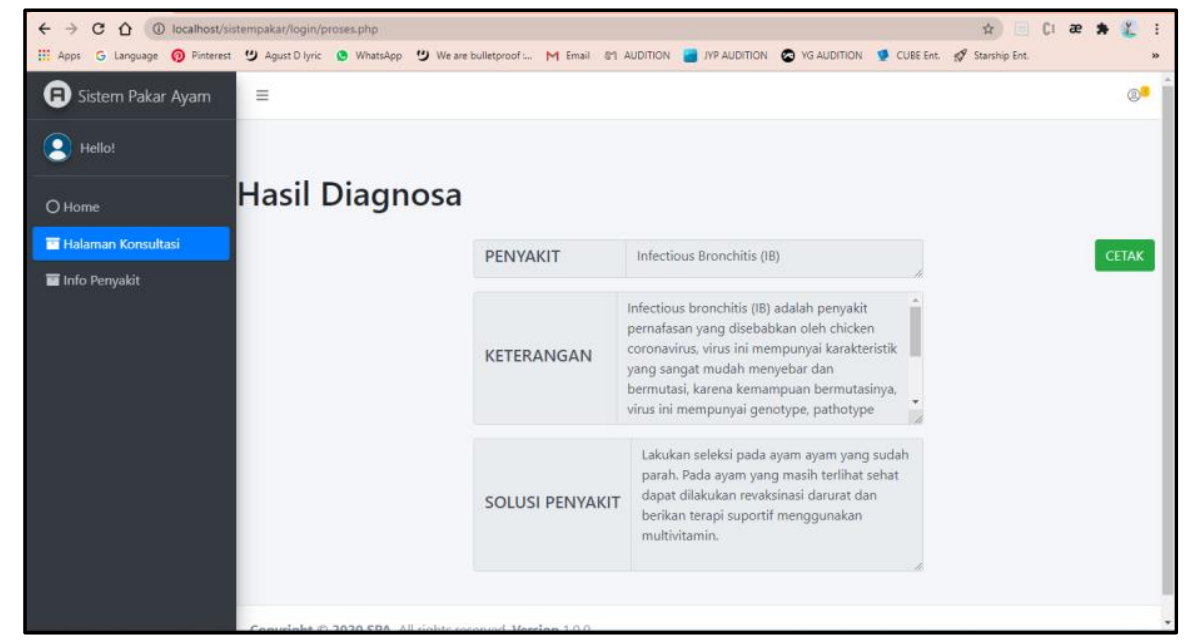

Gambar 5. Tampilan Hasil Diagnosa 


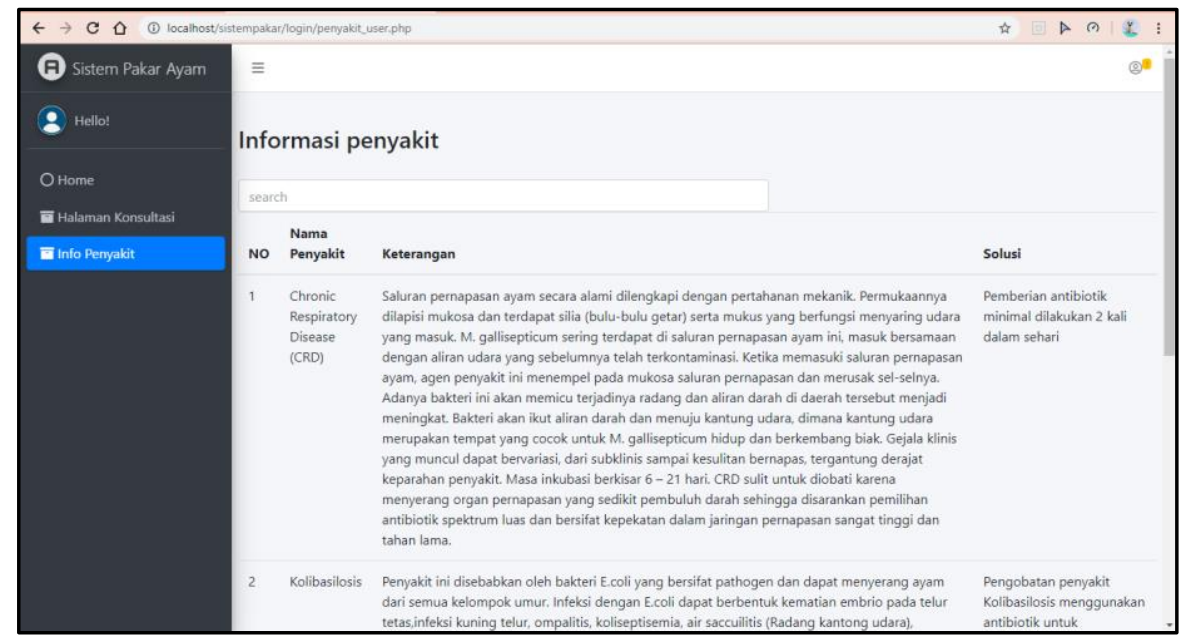

Gambar 6. Tampilan Informasi Penyakit

\section{Pengujian}

Pengujian merupakan suatu tahap untuk menguji system yang dibangun dengan tujuan untuk menguji kelayakan sistem serta melakukan pengecekan jika terdapat kesalahan sehingga akan dilakukan perbaikan (Suandi, Khasanah, \& Retnoningsih, 2017). Langkah pengujian dilakukan guna menguji system apakah terjadi kesalahan maupun kegagalan pada saat sistem dijhalankan (Fitriyani \& Putri, 2017). Pengujian sistem dilakukan dengan dua cara. Pertama dilakukan pengujian dengan metode black box. Pengujian ini merupakan pengujian yang digunakan untuk memeriksa fungsional dari sebuah sistem tanpa menguji desain dan kode program. Pengujian dimaksudkan untuk mengetahui apakah fungsi-fungsi input dan output pada sistem berjalan sesuai fungsinya atau tidak. Berdasarkan pengujian yang dilakukan dengan uji coba terhadap sistem yang melibatkan calon pengguna, diantaranya peternak ayam, penyuluh kesehatan hewan dan pakar hewan, semua fungsi pada sistem telah berfungsi sesuai dengan yang diharapkan sehingga dapat digunakan oleh user. Pengujian black box disajikan pada tabel 2. Hasil tersebut menunjukkan bahawa pengujian dilakukan terhadap metode forward chaining dengan cara membandingkan perhitungan yang ada pada excel dengan perhitungan yang dilakukan pada sistem. Berdasarkan pengujian tersebut diperoleh nilai akurasi sebesar $95 \%$. Selain itu semua data gejala dan penyakit telah berhasil dilakukan pengujian dengan blackbox.

Tabel 2. Hasi Pengujian Black Box

\begin{tabular}{|c|c|c|c|c|}
\hline No & Input & Hasil Yang Diharapkan & Output & Kesimpulan \\
\hline 1 & $\begin{array}{l}\text { Username } \\
\text { dan Password }\end{array}$ & $\begin{array}{l}\text { Masuk ke tampilan } \\
\text { halaman utama }\end{array}$ & $\begin{array}{l}\text { Berhasil masuk ke } \\
\text { tampilan halaman utama }\end{array}$ & Berhasil \\
\hline 2 & Data Gejala & $\begin{array}{l}\text { Sistem dapat menyimpan } \\
\text { data gejala }\end{array}$ & $\begin{array}{l}\text { Data gejala berhasil } \\
\text { disimpan }\end{array}$ & Berhasil \\
\hline 3 & $\begin{array}{l}\text { Data } \\
\text { Penyakit }\end{array}$ & $\begin{array}{l}\text { Sistem dapat menyimpan } \\
\text { data penyakit }\end{array}$ & $\begin{array}{l}\text { Data penyakit berhasil } \\
\text { disimpan }\end{array}$ & Berhasil \\
\hline 4 & Data Gejala & $\begin{array}{l}\text { Sistem menampilkan } \\
\text { hasil diagnosa }\end{array}$ & $\begin{array}{l}\text { Hasil diagnose berhasil } \\
\text { ditampilkan }\end{array}$ & Berhasil \\
\hline 5 & Data Gejala & $\begin{array}{l}\text { Sistem menampilkan } \\
\text { informasi penyakit }\end{array}$ & $\begin{array}{l}\text { Informasi penyakit } \\
\text { berhasil ditampilkan }\end{array}$ & Berhasil \\
\hline 6 & Data Gejala & $\begin{array}{l}\text { Sistem menampilkan } \\
\text { solusi }\end{array}$ & $\begin{array}{l}\text { Solusi berhasil } \\
\text { ditampilkan }\end{array}$ & Berhasil \\
\hline
\end{tabular}




\section{Pembahasan}

Sistem pakar yang dikembangkan dalam penelitian ini menggunakan metode forward chaining untuk melakukan inferensi dengan cara mencari suatu masalah dalam hal ini gejala agar dapat menghasilkan solusi yaitu menemukan penyakit dan cara penangannya. Metode forward chaining ini juga dipakai dalam penelitian yang dilakukan oleh (Honggowibowo, 2009). Akan tetapi penelitian tersebut tidak menjabarkan rule basis pengetahuan secara terperinci menggunakan pohon keputusan. Untuk itu dalam penelitian ini digunakan rule basis pengetahuan yang digambarkan melalui penelusuran dengan pohon keputusan guna menelusuri gejala yang ada pada ayam agar dapat diketahui penyakitnya. Basis pengetahuan didalamnya berisi pengetahuan-pengetahuan untuk menyelesaikan suatu masalah pada domain tertentu dan didalamnya juga dapat mengandung kaidah maupun aturan-aturan yang dapat digunakan untuk memecahkan suatu masalah (Purwanto \& Destiani, 2015). Setelah didapatkan rule basis pengetahuan selanjutnya dibuat rancangan alir data menggunaka data flow diagram (DFD). Pada penelitian ini terdapat 6 proses yaitu proses login, kelola data pengguna, kelola data penyakit, kelola data diagnosa, kelola data rule, kelola data gejala, dan logout. Admin dapat mengelola semua proses yang ada pada system dari data login, data pengguna, data penyakit, data rule, data gejala, data diagnosa, data logout. Pengguna sistem dalam hal ini masyarakat dapat mengelola data diagnosa, karena pengguna dapat melakukan konsultasi pada sistem dengan memasukkan data gejala, sehingga setelah data gejala tersebut dimasukkan maka diperoleh hasil diagnosa. Pengguna sistem dapat melihat informasi mengenai penyakit sebagai pengetahuan tambahan, akan tetapi tidak dapat melakukan modifikasi terhadap data penyakit.

Sistem pakar yang dibangun dalam penelitian ini dilengkapi dengan beberapa fitur diantaranya pengelola halaman pengguna, admin, fitur untuk melakukan konsultasi, menampilkan hasil diagnosa dan juga fitur yang dapat menampilkan informasi penyakit beserta solusi yang dapat dilakukan. Dalam hal ini hasil diagnosa penyakit beserta solusi/cara penanganan dapan ditampilkan setelah pengguna berhasil memasukkan data gejala dan berhasil menyimpannnya pada menu halaman konsultasi. Diagnosa penyakit yang disajikan pada gambar 6 menunjukkan hasil penyakit infectious bronchitis (IB). Hasil tersebut diperoleh berdasarkan gejala yang dimasukkan oleh pengguna yaitu sesak napas, ngorok, keluar lender dari hidung/mulut, bensin, nafsu makan turun dan batuk. Solusi terhadap penyakit juga ditampilkan pada hasil diagnose seperti yang ditampilkan pada gambar 6. Pada sistem pakar ini pengguna juga dapat memperoleh informasi dan penjelasan terkait penyakit pada ayam secara terperinci melalui halaman info penyakit.

Setelah sistem pakar berhasil dibangun selanjutnya dilakukan pengujian dengan black box untuk menguji fungsionalitas sistem. Berdasarkan pengujian yang dilakukan dengan uji coba terhadap sistem yang melibatkan calon pengguna, diantaranya peternak ayam, penyuluh kesehatan hewan dan pakar hewan, semua fungsi pada sistem telah berfungsi sesuai dengan yang diharapkan sehingga dapat digunakan oleh user. Pengujian black box yang telah dilakukan disajikan dalam kesimpulan yang ada pada table 2. Pengujian lain juga dilakukan dilakukan dengan membandingkan perhitungan yang ada pada excel dengan perhitungan yang ada pada sistem.Berdasarkan pengujian tersebut diperoleh nilai akurasi sebesar $95 \%$.

\section{SIMPULAN}

Pengembangan aplikasi sistem pakar berbasis web telah berhasil dibangun dan dapat digunakan untuk melakukan diagnosa terhadap gejala dan penyakit yang sering terjadi pada ayam pedaging dengan hasil yang ditampilkan sesuai dengan rule yang telah ditentukan sebelumnya berdasarkan basis pengetahuan. Basis pengetahuan yang direpresentasikan dalam penelitian ini yaitu menggunakan penelusuran dengan kaidah IF - THEN. Berdasarkan pengujian yang dilakukan dengan uji coba terhadap sistem yang melibatkan calon pengguna, 
diantaranya peternak ayam, penyuluh kesehatan hewan dan pakar hewan, semua fungsi pada sistem telah berfungsi sesuai dengan yang diharapkan sehingga dapat digunakan oleh user. Pengujian terhadap akurasi terhadap metode forward chaining diperoleh nilai akurasi yaitu $95 \%$.

\section{REFERENSI}

Afandi, A. (2018). Sistem Pakar Identifikasi Penyakit Ayam Pedaging. Jurnal Cendikia, $16(1), 58-67$.

Ariyawan, M. D. (2018). Aplikasi Sistem Pakar Diagnosa Penyakit Umum Pada Manusia Berbasis Web. Jurnal Elektronik Ilmu Komputer Udayana, 7(2), 59-67.

Firmansyah, H. B. (2019). Pembangunan Sistem Pakar untuk Diagnosis Penyakit Tulang dan Sendi. Journal of Science and Application Technology, 2(1), 44-52. https://doi.org/10.35472/281487

Fitriyani, A., \& Mahadji, D. (2017). Perancangan Aplikasi Mobile Edukatif 'Belajar Chord Gitar Untuk Pemula' Berbasis Android. Edu Komputika Journal, 4(2), 20-24. https://doi.org/10.15294/edukomputika.v4i2.11215

Fuad, H., \& Susilo, H. (2016). Perancangan Sistem Pakar Diagnosa Penyakit Ayam Dengan Metodologi Berbasis Objek. Jurnal Sisfotek Global, 6(1). 17-20.

Honggowibowo, A. S. (2009). Sistem pakar diagnosa penyakit tanaman padi berbasis web dengan forward dan backward chaining. Telkomnika, 7(3), 187-194.

Ibrohim, M., \& Purwanty, N. (2017). Rancang Bangun Aplikasi Identifikasi Gaya Belajar Siswa Dengan Metode Forward Chaining (Studi Kasus: Sekolah Dasar Negeri Sumampir ). Jurnal ProTekInfo, 4(1), 19-28.

Ifriza, Y., Elektro, J. T., Teknik, F., \& Semarang, U. N. (2015). Perancangan Sistem Pakar Penyuluh Diagnosa Hama Padi dengan Metode Forward Chaining. Jurnal Teknik Elektro Unnes, 7(1), 30-36. https://doi.org/10.15294/jte.v7i1.8590

Jarti, N., \& Trisno, R. (2017). Sistem Pakar Diagnosa Penyakit Alergi Pada Anak Berbasis Web dengan Metode Forward Chaining. Jurnal Edik Informatika, 3(2), 197-205.

Ongko, E. (2014). Perancangan Sistem Pakar Diagnosa Penyakit Pada Balita. Jurnal Time, II(1), 1-5. https://doi.org/10.1007/s13398-014-0173-7.2

Purwanto, T., \& Destiani, D. (2016). Pengembangan Sistem Pakar Diagnosis Penyakit Cabai Paprika Berbasis Android. Jurnal Algoritma, 13(1), 191-197. https://doi.org/10.33364/algoritma/v.13-1.191

Rohajawati, S., \& Supriyati, R. (2010). Sistem Pakar: Diagnosis Penyakit Unggas Dengan Metode Certainty Factor. CommIT (Communication and Information Technology) Journal, 4(1), 41-46.

Rosa, A., S. \& Shalahuddin, M. (2016). Rekayasa Perangat Lunak. Bandung: Informatika.

Salman, F. M., \& Abu-Naser, S. S. (2019). Expert System for Castor Diseases and Diagnosis. International Journal of Engineering and Information Systems (IJEAIS), 3(3), 1-10.

Septiani, M., \& Kuryanti, S. J. (2019). Sistem Pakar untuk Mendiagnosa Penyakit Saluran Pernapasan pada Anak. SinkrOn. 2(2), 23-27.

Suandi, A., Khasanah, F. N., \& Retnoningsih, E. (2017). Pengujian Sistem Informasi Ecommerce Usaha Gudang Cokelat Menggunakan Uji Alpha dan Beta. Information System for Educators and Professionals, 2(1), 61-70. 